\title{
Acceleration of coxarthrosis by an exostosis causing femoroacetabular impingement
}

\author{
Mahmut Nedim Aytekin ${ }^{1}$, Hakan Atalar ${ }^{1}$, Burcu Yanik ${ }^{2}$, Murat Arikan ${ }^{3}$ \\ ${ }^{1}$ Department of Orthopedics and Traumatology, Fatih University Hospital, Ankara, Turkey; nedimaytekin@hotmail.com \\ ${ }^{2}$ Department of Physical Therapy and Rehabilitation, Fatih University Hospital, Ankara, Turkey \\ ${ }^{3}$ Department of Orthopedics and Traumatology, Ankara Oncology State Hospital, Ankara, Turkey
}

Received 18 November 2009; revised 4 January 2010; accepted 8 January 2010.

\begin{abstract}
Here we describe a 28-year-old man with a history of right hip pain for the past $\mathbf{1 1}$ years and ankylosing spondylitis for the past 6 months. Imaging studies showed an exostosis in the femoral neck causing femoroacetabular impingement. The patient was diagnosed with coxarthrosis. This case report suggests that femoroacetabular impingement may accelerate the degenerative process in the hip joint.
\end{abstract}

Keywords: Femoroacetabular Impingement; Exostosis

\section{INTRODUCTION}

Femoroacetabular impingement, also known as hip impingement syndrome, refers to a condition in which the femoral head-neck junction impinges upon the acetabulum, thereby being a potential cause of hip osteoarthritis $[1,2]$. Two types of impingement are defined according to the anatomic structures involved. Cam impingement occurs when the contact arises from an abnormality in the femur and pincer impingement is defined as that which results when the abnormality originates from the acetabulum [3]. Both types are characterized by damage to the acetabular labrum and articular cartilage in the hip $[4,5]$. These changes lead to degenerative osteoarthritis in the long term $[5,6]$. Here, we describe a patient who has femoroacetabular impingement due to a bone mass in the femoral neck and coxarthrosis. We could not found any case which demonstrates acceleration of coxarthrosis by an exostosis causing femoroacetabular impingement in the literature.

\section{CASE REPORT}

A 28-year-old male presented at our hospital with a history of right hip pain for the past 11 years which had become increasingly worse in the past 3 years, up to the point at which he decided to seek treatment. He was cur- rently working as a waiter. Six months prior to this presentation he had been diagnosed with ankylosing spondylitis and was currently taking salazoprine, methotrexate and indomethacin regularly. He was a nonsmoker and had no history of athletic activity which could explain his findings. He also reported having back pain and morning stiffness for the past 3 years.

On physical examination of the right hip, flexion, abduction, external rotation and external rotation were limited. There was 45 degree maximum flexion, 10 degree maximum extension and 10 degree maximum abduction in the right hip joint. Internal and external rotation of the right hip was also markedly restricted. Anteflexion, extension and lateral bending of the lumbar region were limited.

Pelvic x-ray showed an exostosis in the right femoral neck. Also visible in the right hip were narrowing of the hip joint, subchondral sclerosis and osteophytes. There was also sclerosis and narrowing in the sacroiliac joint, indicating bilateral sacroileitis which is a finding of ankylosing spondylitis (Figure 1). CT and MRI demonstrated

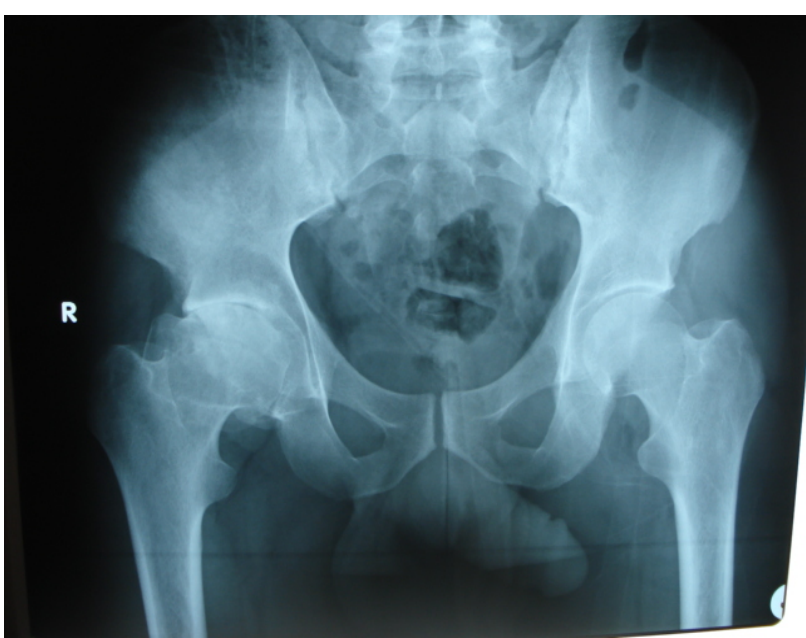

Figure 1. An anteroposterior pelvic radiograph shows cam impingement due to exostosis of the femoral neck and coxarthrosis in the right hip. 
femoroacetabular impingement caused by the exostosis (Figures 2,3).

Conservative treatment has been decided upon for the time being because the patient is young and can still perform his activities of daily life.

\section{DISCUSSIONS}

Femoroacetabular impingement has been recognized as

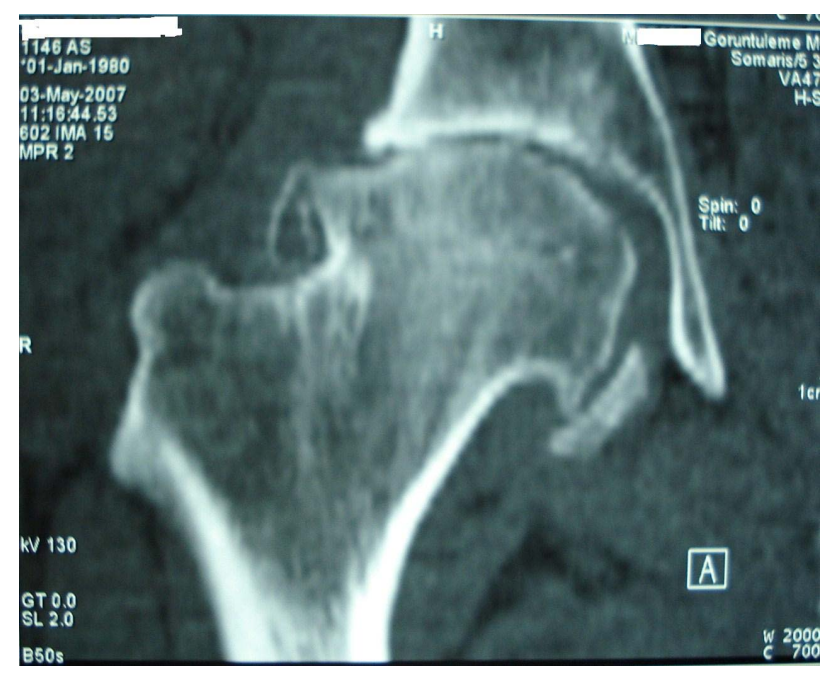

Figure 2. Coronal computed tomography of the right hip demonstrates femoroacetabular cam impingement due to an exostosis in the femoral neck and findings of coxarthrosis.

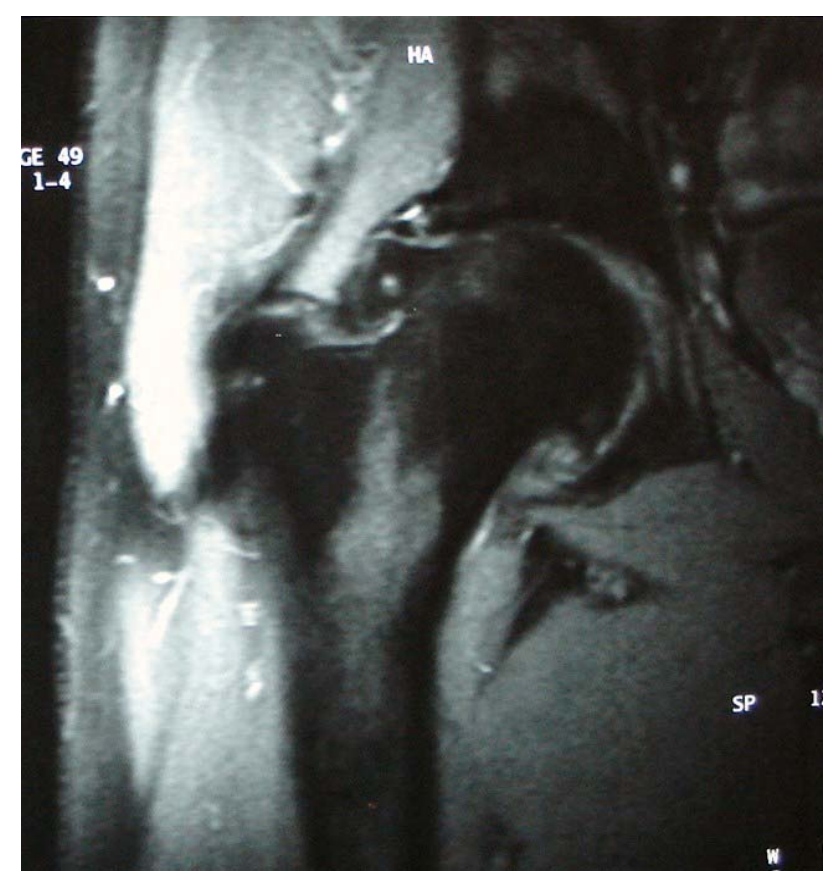

Figure 3. Magnetic Resonance Imaging of the right hip demonstrates femoroacetabular cam impingement due to an exostosis in the femoral neck and findings of coxarthrosis. an underlying cause of hip pain and secondary osteoarthritis [1] and occurs in two main forms: cam-type impingement and pincer-type impingement. Cam-type impingement occurs when the anterior femoral neck abnormally impinges on the on the acetabulum and labrum, resulting in damage to the labrum $[7,8]$. Pincer-type impingement occurs when an osteophyte on the anterior acetabulum impinges on the anterior femoral neck during hip flexion or retroversion of the acetabulum $[9,10]$.

We found cam-type impingement due to the exostosis on the femoral neck in our patient. For the coxarthrosis that developed, another possible etiological factor was the ankylosing spondylitis; however, the patient had no other risk factors for coxarthrosis such as smoking, alcoholism, steroid use, obesity, female gender, repetitive occupational trauma, or neuromuscular or metabolic disorders. Protrusio acetabuli may develop in as many as one third of patients and hip joint involvement typically is bilateral and symmetric. Absence of the protrusion of the both acetabulum and the unilateral nature of the coxarthrosis suggest that the impingement caused by the exostosis had accelerated the degeneration of the hip joint.

Although there are a range of treatment options for hip impingement syndrome [1], nonsurgical treatment generally does not control symptoms [11]. By preventing microtrauma, early treatment may help preserve the joint by averting the impingement that may lead to coxarthrosis [8]. Our patient presented later in the course of the disease, with hip osteoarthritis symptoms that were apparently due indirectly to the nearby tumor, which itself was not painful.

In conclusion, femoral neck exostosis may accelerate the progression of coxarthrosis by cam impingement. Early diagnosis is therefore important in preventing this degenerative process.

\section{REFERENCES}

[1] Dooley, P.J. (2008) Femoroacetabular impingement syndrome: Nonarthritic hip pain in young adults. Canadian Family Physician, 54(1), 42-47.

[2] Standaert, C.J., Manner, P.A. and Herring, S.A. (2008) Expert opinion and controversies in musculoskeletal and sports medicine: Femoroacetabular impingement. Archives of Physical Medicine and Rehabilitation, 89(5), 890-893.

[3] Kassarjian, A., Brisson, M. and Palmer, W.E. (2007) Femoroacetabular impingement. European Journal of Radiology, 63(1), 29-35.

[4] Philippon, M., Schenker, M., Briggs, K. and Kuppersmith, D. (2007 July) Femoroacetabular impingement in 45 professional athletes: Associated pathologies and return to sport following arthroscopic decompression. Knee Surgery, Sports Traumatology, Arthroscopy, 15(7), 908914.

[5] Tannast, M., Goricki, D., Beck, M., Murphy, S.B. and 
Siebenrock, K.A. (2008) Hip damage occurs at the zone of femoroacetabular impingement. Clinical Orthopaedics and Related Research, 466(2), 273-280.

[6] Parvizi, J. and Purtill, J.J. Hip, pelvic reconstruction, and arthroplasty. Orthopedic Knowledge Update, 8(34), 412.

[7] Ganz, R., Parvizi, J., Beck, M., Leunig, M., Nötzli, H. and Siebenrock, K.A. (2003) Femoroacetabular impingement: A cause for osteoarthritis of the hip, Clinical Orthopaedics and Related Research, 417, 112-120.

[8] Ito, K., Minka, M.A. Leunig, M., Werlen, S. and Ganz, R. (2001) Femoroacetabular impingement and the cam-effect: A MRI based quantitative anatomical study of the femoral head-neck offset. Journal of Bone and Joint Surgery, British Volume, 83, 171-176.
[9] Beck, M., Kalhor, M., Leunig, M. and Ganz, R. (2005) Hip morphology influences the pattern of damage to the acetabular cartilage: Femoroacetabular impingement as a cause of early osteoarthritis of the hip. Journal of Bone and Joint Surgery - British Volume, 87, 1012-1018.

[10] Beck, M., Leunig, M., Parvizi, J., Boutier, V., Wyss, D. and Ganz, R. (2004 January) Anterior femoroacetabular impingement: Part II. Midterm results of surgical treatment. Clinical Orthopaedics and Related Research, 418, 67-73.

[11] Parvizi, J., Leunig, M. and Ganz, R. (2007) Femoroacetabular impingement. Journal of the American Academy of Orthopaedic Surgeons, 15(9), 561-570. 